\title{
Journal of Bone Biology and Osteoporosis Effects of Chromeceptin on Insulin-like Growth Factor II in Human Osteoblastic and Osteosarcoma Cells
}

\author{
Nourah $D^{1}$, AlHousami $T^{1}$, Nguyen $D^{2}$ and Dziak $\mathbf{R}^{\mathbf{2}^{*}}$ \\ ${ }^{1}$ Oral Sciences Program, University at Buffalo School of Dental Medicine, USA \\ ${ }^{2}$ Department of Oral Biology, University at Buffalo School of Dental Medicine, USA
}

*Correspondence: Rosemary Dziak, Department of Oral Biology, University at Buffalo School of Dental Medicine, 318 Foster Hall, 3435 Main Street, Buffalo, NY, USA, Tel: 716-8293827; Fax: 716-8293840; E-mail: rdziak@buffalo.edu

Rec date: July 13, 2018; Acc date: Aug 07, 2018; Pub date: Aug 12, 2018

\begin{abstract}
The insulin-like growth factor system is a complex regulatory system of insulin-like growth factors I and II (IGF-I and IGF-II) as well as their cell surface receptors and a family of insulin growth factor binding proteins (IGF-BPs). Despite extensive research on the IGF system in skeletal tissue, there is still not a complete understanding particularly of the role of IGF-II in the regulation of normal and pathological osseous cells in human skeletal biology. The purpose of this study was to further delineate the possible involvement of IGF-II in the regulation of human normal calvarial osteoblasts and G292 human osteosarcoma cellular activity using exogenously added IGF-II as well as a drug, Chromeceptin that has been shown in some other cellular systems to down regulate endogenous IGF-II levels.
\end{abstract}

The results presented here show a similar dose dependent effect of Chromeceptin on inhibition of endogenous IGF-II levels (measured with an immunoassay) and cellular activity (measured with the MTT assay) in both the normal and osteosarcoma cells while small significant increases in activity with exogenously added IGF-II were observed only in the osteosarcoma cells. Moreover, IGF-BP1 levels (measured with an immunoassay) were shown to significantly increase in the G292 cells in a similar manner previously reported in other cell systems with only minor non-significant effects of exogenously added IGF-BP1 in the osteosarcoma cells studied here. These studies suggest that endogenous IGF-II is a critical regulator of activity in both normal and osteosarcoma cells and Chromeceptin can be an effective pharmacological agent for further studies on the role of the growth factor in human skeletal systems.

Keywords: Insulin-like growth factor, Chromeceptin, Osteoblasts, Osteosarcoma cells

Abbreviations: IGF-II: Insulin-like Growth Factor II; IGFBP: Insulin-like Growth Factor Binding Protein; MTT: 3-(4, 5-dimethylthiazolyl-2)-2,5-diphenyltetrazolium bromide

\section{Introduction}

Insulin-like growth factors (IGFs) have been shown in a number of studies conducted over the past four decades to play an important role in the regulation of both physiological and pathological processes in the skeleton.

J Bone Biol Osteoporosis, 4(1): 59-67 (2018) ,
IGFs are part of a complex regulatory system that consists not only of IGF-I and II, but also their cell surface receptors (IGFRs) and insulin-like growth factor binding proteins (IGFBP). A comprehensive review of the research that has revealed critical information on the role of the IGF 
system in the regulation of the skeleton has recently been published [1].

IGFs are considered major components of both the organic skeletal matrix and the circulation. In the serum of most mammals there are significant concentrations of both IGF-I and IGF-II, bound to high and low molecular weight IGFBPs with $\leq 1 \%$ of total serum IGF-I circulating as a free hormone [2]. IGF-II is the predominant circulating IGF that is present in adult humans at a level three times that of IGF-I. The IGFs act in different patterns either as endocrine or autocrine or paracrine pathways to regulate proliferative and differentiating functions of both osteoblasts and osteoclasts [2]. Some studies with human osteoblast-like cells have reported that IGF-I and -II are equally potent in stimulating cell proliferation [3], while others found that IGF-I has a more pronounced proliferative effect than both IGF-II and sex steroids [4]. IGF-I and IGF-II have been described as mediators of at least part of the effects on bone turnover of several hormones, such as growth hormone, estrogen, parathyroid hormone, and glucocorticoid. Bone morphogenetic proteins increase IGF-I and II mRNA expression in osteoblastic cells and may be a critical factor in early recruitment of osteoblasts within the remodeling unit [5]. Transforming growth factor beta (TGF-B) increases IGF-I and IGFBP-3 expression in human marrow stromal cells. Prostaglandins regulate IGF-I and -II expression and are produced by osteoblasts, thereby providing a major paracrine regulatory circuit in the skeleton $[1,6,7]$. During bone resorption, as the matrix is dissolved, significant amounts of IGF-I and II are released. Consequently both IGFs recruit precursor osteoblasts and possibly early osteoclasts to the bone surface where remodeling is occurring [1].

In addition to its expression in normal cells, IGF-II, as well as IGFR1R and IGF-I, is over-expressed in and has been implicated as an autocrine growth factor for many cancerous conditions including breast cancer, hepatocellular carcinoma, prostate cancer, pancreatic cancer, melanoma and Ewing sarcoma as recently review [8]. There is extensive evidence that increased IGF-II expression by tumors is associated with a poorer prognosis [8]. Moreover, IGF ligands can be delivered to IGF-1Rs from exogenous (endocrine) or nearby (paracrine) sources, with circulating free-ligand levels regulated by the different IGFBPs. The involvement of IGF-II in human malignancies suggests that the molecular analysis of IGF-II regulation may provide a better understanding of a new therapeutic approach for various cancers and this growth factor has received considerable attention as a target for pharmaceutics that inhibit the IGF system.

Chromeceptin is a synthetic small benzochromene derivative that impairs the function of IGF-II and inhibits IGF-II over expression and growth and viability of hepatocellular carcinoma cells. Chromeceptin has also been shown to inhibit insulin-induced adipogenesis through its effect on IGF-II expression [9]. It has been demonstrated by molecular biological approaches that Chromeceptin acts by blocking the autocrine loop of IGF-II [10]. The mechanism of Chromeceptin has been shown to involve its binding to multifunctional protein 2 (MFP-2) which then stimulates the expression of IGF binding protein 1 (IGFBP-1) and suppression of cytokine signaling-3 (SOCS-3), and resultant activation of signal transducers and activators of transcription 6 (STAT6) to attenuate IGF signals [10]. To date, studies on the effects of Chromeceptin on osseous cells have been limited although Fanganiello et al. [11] did utilize it in their work delineating the osteopotential of mesenchymal stem cells extracted from human deciduous teeth and human adipose tissue.

In this present work, the effects of Chromeceptin on the activity of both normal human osteoblastic cells as well as an osteosarcoma cell line, G292, are described with emphasis on the role of IGF-II. Since there are indications that IGF-II has an important role in regulation of normal human osteoblast activity and differentiation through endogenous and exogenous effects as well as in the regulation of the activity of osteosarcoma cells [3,4,12], a drug that modulates the IGF-II pathways should be a useful tool in further delineating the regulatory pathways of this growth factor in both normal and pathological skeletal events.

\section{Materials and Methods}

Human osteoblast cells were purchased as primary calvarial cells from ScienCell (CA, USA).

G-292 (Clone A141B1) human osteosarcoma cells were purchased from American Type Culture Collection (ATCC, VA, USA).

Recombinant human insulin growth factor II (rhIGFII), rhIGF-BP1 and Chromeceptin (2-Amino-3-cyano-7dimethylamino-4-(3 trifluoromethylphenyl)-4H-chromene, 94G6) were purchased from Sigma Aldrich (St Louis, MO, USA). Quantikine human IGF-II and IGFBP-1 immunoassay kits were commercially obtained from R\&D Systems (Minn, MN, USA). Unless otherwise stated, chemicals and culture reagents were purchased from Sigma Aldrich. 


\section{Cell culture}

Normal human osteoblasts were cultured in minimum essential medium-alpha (MEM-a) supplemented with $10 \%$ heat inactivated Fetal Bovine Serum (FBS) (Upstate Biotechnology, Lake Placid, NY, USA) and $1 \%$ antibiotics (MEM complete medium). Cells were washed in $6 \mathrm{ml}$ of complete medium and seeded into a $75 \mathrm{ml}$ culture flask. Cells were maintained in a 5\% CO2 incubator at 370C and medium changes were made every 3 days until the culture reached confluence. In order to subculture cells, complete medium was removed and cells were detached from the bottom of the flask by exposure to $0.25 \%$ trypsin for 3 mins and the enzyme was neutralized with complete medium. Cells were centrifuged at 1000 rpm for 5 mins, cell pellet re-suspended in $12 \mathrm{ml}$ of complete medium and seeded into two $75 \mathrm{ml}$ fresh culture flasks.

Similar culture and sub culturing conditions were used for the G292 cells with the exception for the use of McCoy's 5A (modified) medium supplemented with $10 \%$ heat inactivated FBS (Upstate Biotechnology, Lake Placid, NY) and $1 \%$ antibiotics (McCoy's complete medium).

\section{MTT assay}

Cell activity was assessed with the MTT assay using a protocol that has been previously described [13]. After incubation of the cells in 96 well culture plates (Corning, NY, USA) under the particular experimental conditions to be tested, the medium was removed from each well and replaced with Minimum Essential Medium (MEM) without phenol red and appropriate amounts of yellow tetrazolium MTT (3-(4, 5-dimethylthiazolyl-2)-2,5-diphenyltetrazolium bromide) followed by incubation for 2 to 4 hours for reduction of MTT by metabolically active cells. Following solubilization of the MTT crystals with dimethylsulfoxide (DMSO), the absorbance of the samples was obtained with a Bio-Rad $®$ micro plate spectrophotometer (Bio-Rad laboratories, NY, USA) at $540 \mathrm{~nm}$ wavelength.

\section{Alkaline Phosphatase Activity}

After incubation of the normal osteoblastic cells under the particular experimental conditions, the medium was removed from the tissue culture wells followed by the addition of $1 \%$ Triton X-100 (200 $\mu \mathrm{L})$ to each well. After incubation for $1 \mathrm{hr}$ at $40^{\circ} \mathrm{C}$, the Triton was removed and p-nitrophenylphosphate (pNPP) and 2-amino -2-methylpropanol buffer were added in to each well as previously described in detail [14]. After incubation for $1 \mathrm{hr}$ at $37^{\circ} \mathrm{C}$, the reaction was ended with the addition of $\mathrm{NaOH}$ and absorbance of the final product was obtained with a Bio-
Rad $^{\circledR}$ micro plate spectrophotometer (Bio-Rad Laboratories, NY, USA) at $405 \mathrm{~nm}$ wavelength.

\section{IGF-II and IGFBP-1 Endogenous Levels}

After incubation under the appropriate experimental conditions, the cells were lysed and immunoassays (ELISA) assays conducted for either IGF-II or IGFBP-1 levels according to the instructions of the commercial supplier.

\section{Statistical analyses}

Statistical differences between control and treated cells were evaluated using Microsoft Excel using one-way analysis of variance (ANOVA) for comparison. All values were expressed as means \pm standard deviation (SD) of six samples in each group; $\mathrm{P}<0.05$ was considered statistically significant.

\section{Results}

\section{Exogenously added IGF-II and MTT activity: no effects in normal osteoblastic cells and small significant increases in osteosarcoma cells}

The effect of exogenously added IGF-II on osteoblast cell activity was studied with the MTT assay in cells incubated with the growth factor for 24 and 48 hours. The cells were incubated in MEM complete medium with two different concentrations of IGF-II (50 ng/ml, $100 \mathrm{ng} / \mathrm{ml})$ that are in the range of effective concentrations in other osteoblastic cell systems [15]. Figure 1 shows that neither concentration of IGF-II had any significant effect in normal osteoblastic cells after the $24 \mathrm{hrs}$ time period of incubation. A similar lack of effect was noted after 48 hrs (data not shown). In the G292 osteosarcoma cells under similar incubation conditions (McCoy's complete medium) with IGF-II there was a slight, but statistically significant $(P<0.05)$ increase in activity with IGF-II added at $50 \mathrm{ng} / \mathrm{ml}$ for $24 \mathrm{hrs}$ as shown in figure 2.

\section{Decreases in osteoblastic cell activity with chromeceptin}

The effects of Chromeceptin on metabolic activity, assessed with the MTT assay after $24 \mathrm{hrs}$ incubation with the drug, were similar in both normal osteoblastic cells and the G292 osteosarcoma cells. As shown in figures 3 and 4, Chromeceptin added at concentrations of 0.3, 1.0, 3.0 and $5.0 \mu \mathrm{M}$ significantly decreased the activity of the G292 cells while in the normal osteoblastic cells decreases were observed with $0.3,1.0$ and $3.0 \mu \mathrm{M}$ concentrations with no significant effects at $5.0 \mu \mathrm{M}$. Although the relative decreases compared to controls were less in the normal 
cells compared to those in the G292 cells, in both cell types, Chromeceptin at a concentration of $0.3 \mu \mathrm{M}$ produced the largest inhibitory effect.

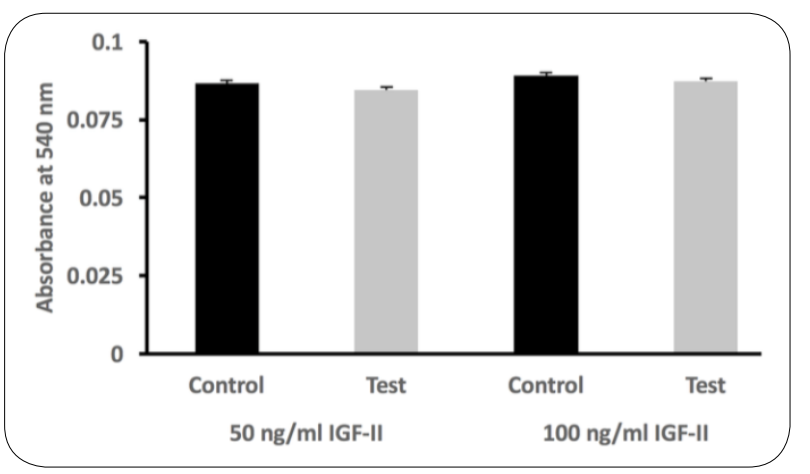

Figure 1: No significant effect of exogenously added IGF-II on osteoblastic cell activity: MTT assay in normal osteoblastic cells: Activity was assessed with two concentrations of IGF-II ( $50 \mathrm{ng} / \mathrm{ml}$ and $100 \mathrm{ng} / \mathrm{ml}$ ) added to the cells incubated under standard conditions for $24 \mathrm{hrs}$. No significant differences in comparison to the appropriate control (medium diluted with IGF-II solvent only) were found, $P>0.05$. Values represent the means $+/$ - standard deviations; $\mathrm{n}=6$.

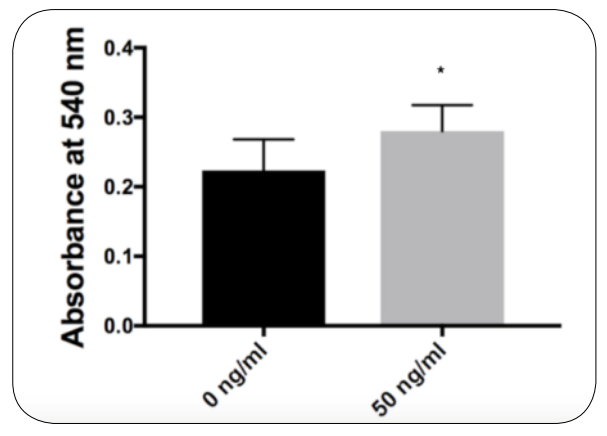

Figure 2: Slight increase of exogenously added IGFIl on osteosarcoma cell activity: MTT assay in G292 osteosarcoma cells: Activity was assessed with IGF-II ( $50 \mathrm{ng} / \mathrm{ml}$ ) added to the cells incubated under standard conditions for $24 \mathrm{hrs}$. A small significant difference in comparison to the control (medium diluted with IGF-II solvent only) was found ( $*=P<0.05$ ). Values represent the means $+/$ - standard deviations; $n=6$.

\section{Chromeceptin decreases endogenous levels of IGF-II}

When normal osteoblast cells were incubated with MEM complete medium for 24 hours with chromeceptin at concentrations $(0.3 \mu \mathrm{M}, 1.0 \mu \mathrm{M}$, and $5.0 \mu \mathrm{M}$ there was a significant decrease in endogenous levels of IGFII compared to controls with all tested groups as shown in figure 5. The dose response strongly resembled what was obtained in the cell activity studies with $0.3 \mu \mathrm{M}$ Chromeceptin producing the greatest effect (Figure 5). It should be noted that despite the fact that the control levels of IGF-II in the G292 cells were substantially higher than in the normal osteoblasts, these osteosarcoma cells responded in a similar manner to Chromeceptin treatment with significant decreases in endogenous levels of IGF-II after a $24 \mathrm{hr}$ incubation period with the drug (Figure 6).

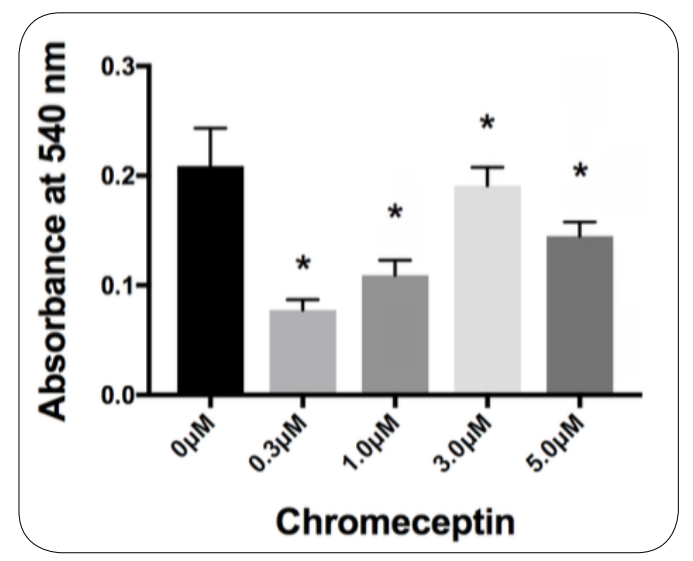

Figure 3: Chromeceptin produced decreases in cell activity: MTT assayinG292 osteosarcoma cells: Activity was assessed with Chromeceptin added to the cells for 24 hrs. Chromeceptin significantly $(P<0.05)$ decreased the activity at all the concentrations tested. Values represent the means \pm standard deviations; $n=6$.

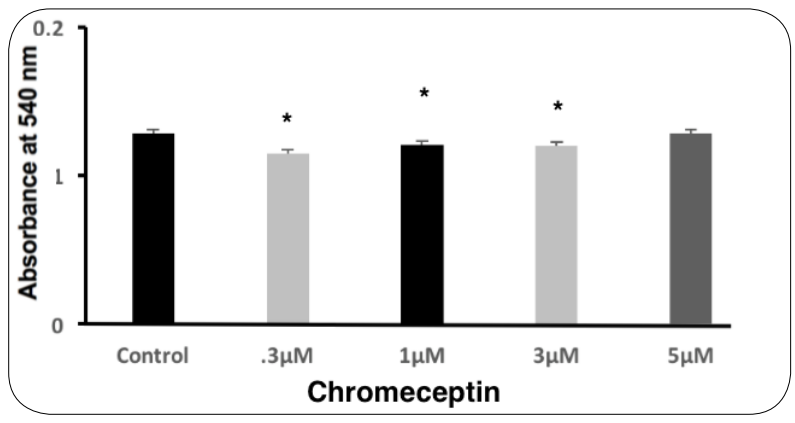

Figure 4: Chromeceptin produced decreases in cell activity: MTT assay in normal osteoblastic cells: Activity was assessed with Chromeceptin added to the cells for $24 \mathrm{hrs}$. Chromeceptin significantly $(P<0.05)$ decreased the activity at all the concentrations tested with the exception of $5 \mu \mathrm{M}$ that had no significant effect $(P>0.05)$. Values represent the means \pm standard deviations; $n=6$. 


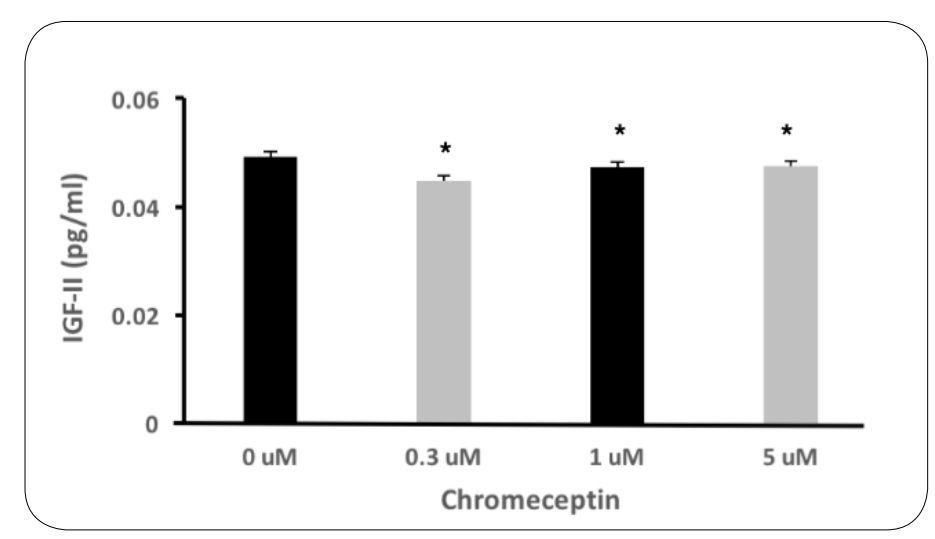

Figure 5: IGF-II levels: decreases with Chromeceptin in normal osteoblastic cells: IGF-II levels were measured with an immunoassay after cells were treated with Chromeceptin for $24 \mathrm{hrs}$. There was a significant decrease in IGF-II levels compared to controls ( 0 Chromeceptin) with all added concentrations. * = $P<0.05$. Values represent the means $+/$ - standard deviations; $n=6$.

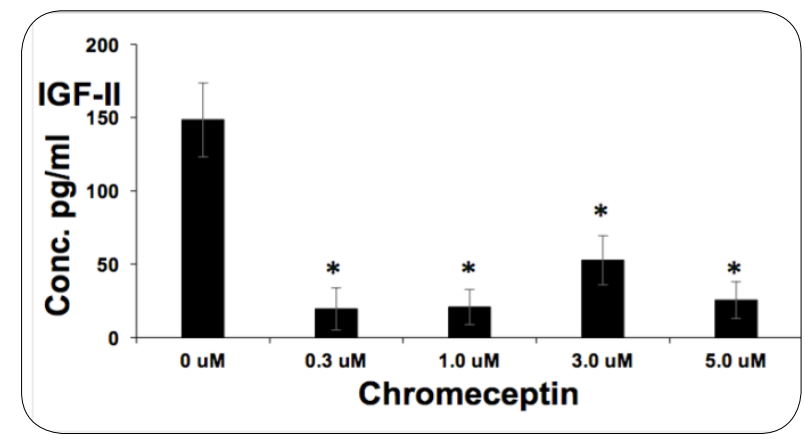

Figure 6: IGF-II levels: decreases with Chromeceptin in G292 osteosarcoma cells: IGF-II levels were measured with an immunoassay after cells were treated with Chromeceptin for $24 \mathrm{hrs}$. There was a significant decrease in IGF-II levels compared to controls ( 0 Chromeceptin) with all added concentrations. * = $P<0.05$. Values represent the means $+/$ - standard deviations; $\mathrm{n}=6$.

\section{Alkaline Phosphatase activity studies: no effects of exogenous IGF-II or chromeceptin}

Since Alkaline Phosphatase is considered a marker of early differentiation in normal osteoblastic cells, studies were conducted on the effects of exogenous IGF-II as well as Chromeceptin on this parameter. Figures 7 and 8 show that after $72 \mathrm{hr}$ of incubation with either IGF-II at $50 \mathrm{ng} / \mathrm{ml}$ or Chromeceptin (0.3 or $3.0 \mu \mathrm{M})$ no significant effects on this parameter were observed.

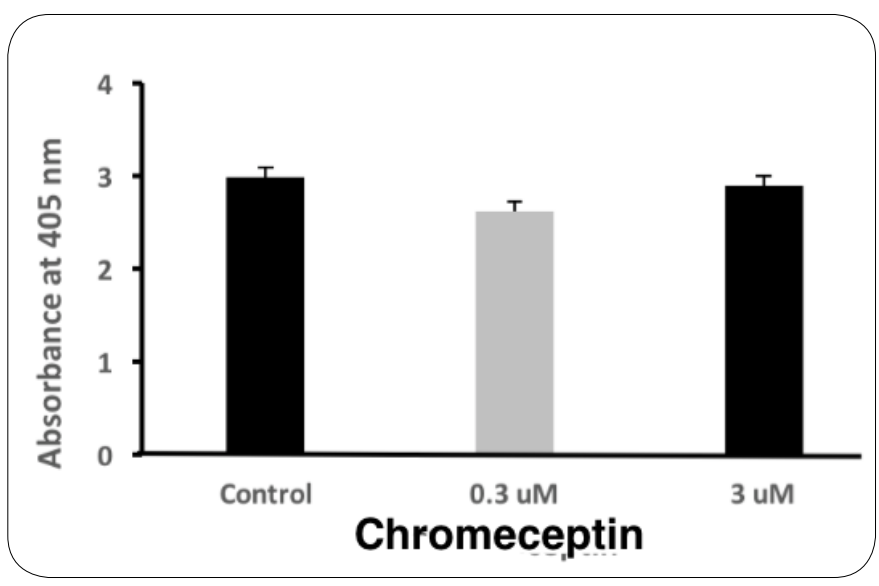

Figure 7: Alkaline Phosphatase activity: no significant effects with Chromeceptin in normal osteoblastic cells: Incubation with Chromeceptin for 72 hrs produced a small, but non-significant decrease with $0.3 \mu \mathrm{M}$ but no significant effects compare to controls were observed with either Chromeceptin concentration tested $(P$ $>0.05)$. Values represent the means $+/$ - standard deviations with $n=6$.

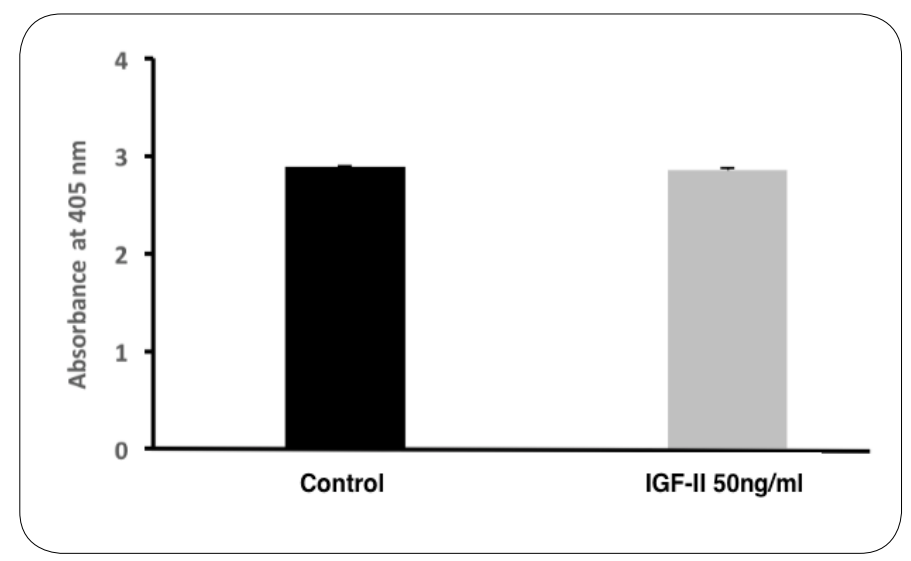

Figure 8: Alkaline Phosphatase activity: no effects with IGF-II in normal osteoblastic cells: Incubation with IGF-II at $50 \mathrm{ng} / \mathrm{ml}$ for $72 \mathrm{hrs}$ produced any significant effect compare to controls $(P>0.05)$. Values represent the means $+/$ - standard deviations with $n=6$.

\section{IGFBP-1 studies: no effect of exogenously added IGFBP-1 on MTT activity; chromeceptin increases endogenous levels of IGFBP-1}

The addition of IGFBP-1 at a concentration of $50 \mathrm{ng} /$ $\mathrm{ml}$ to the incubation medium for $24 \mathrm{hr}$ had no significant effect on cellular activity in either the normal osteoblastic cells or G292 osteosarcoma cells (data not shown). When the effects of chromeceptin $(0.3 \mu \mathrm{M})$ on endogenous levels of IGFBP-1 were tested in the G292 cells after 24 hr incubation, however, there was a small, but significant 
increase (Figure 9).

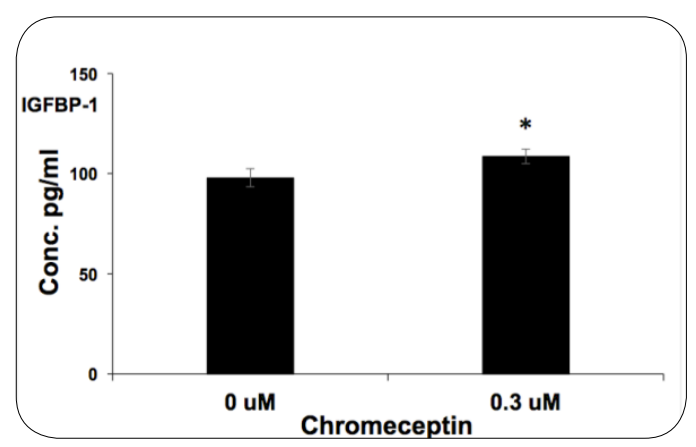

Figure 9: IGFBP-I levels: increases by chromeceptin in G292 osteosarcoma cells: IGFBP-1 levels were measured with an immunoassay after incubation of the cells with chromeceptin $(0.3 \mu \mathrm{M})$ for $24 \mathrm{hrs}$. A significant increase compared to controls was observed with the chromeceptin treatment. ${ }^{*}=P<0.05$; values are the means \pm standard deviations, $\mathrm{n}=6$.

\section{Discussion}

The overall goal of this study was to further delineate the role of IGF-II in the regulation of human osteoblastic cell regulation and investigate possible differences between the effects of this growth factor on normal osteoblasts and osteosarcoma cells. After over four decades of extensive research focusing on the role of insulin-like growth factors utilizing multifaceted approaches in many different animal and human models, it appears as noted in a recent comprehensive review [1], that the effects of IGF-II on the adult and aged human skeleton are still not completely understood.

A number of studies with different model systems have shown that IGF-I and IGF -II stimulate osteoblastic cell proliferation and differentiation. The results from these studies can seem somewhat contradictory if the species differences and state of the cellular populations used in the studies are not considered. For example, Mohan \& Baylink [16] showed that IGF-II is the most abundant IGF in human bone whereas IGF-I is most prevalent in rats. Likewise, the IGFs and their binding proteins are synthesized in different amounts in rat and human osteoblasts Mohan et al. reported that one of the major effects of IGFs on osteoblasts is stimulation of cell proliferation [17] whereas McCarthy et al reported the effect of IGFs on collagen production [18]. Wergedal et al. observed that in normal human osteoblast-like cells both IGF-I and IGF-II have equal stimulatory effects on cell proliferation [3], whereas Verhaar et al. reported that IGF-I has more of a marked proliferative effect than IGF-II [4]. Langdahl et al. conducted a study of the effects of IGF-I and IGF-II on the proliferation and differentiation of human osteoblasts and interactions with growth hormone on human osteoblast-like cells from trabecular specimens (HOB) and human marrow stromal cells (HMS) [19]. Their results showed that stimulation with IGF-I increased [3H]-thymidine incorporation in $\mathrm{HOB}$ and in HMS, whereas stimulation with a range of concentrations of IGF-II (1-100 ng/ml) produced an increase in [3H]-thymidine incorporation in HOB but that the effects of exogenous IGF-II in HMS were more limited. Incubations with IGF-I and IGF-II did not alter osteocalcin production and there was no significant alteration in the production of collagen. IGF-I produced a reduction in the alkaline phosphatase production in HOB but there was no significant change in HMS. Alkaline phosphatase production was not altered by stimulation with IGF-II in HOB, but increased in HMS. These studies suggest that the effects of IGF-I and IGF-II can be dependent upon the state of differentiation of bone cells particularly with respect parameters such as alkaline phosphatase. In our present study, IGF-II was tested at concentrations of 50 and $100 \mathrm{ng} / \mathrm{ml}$ because in general the proliferative effects of this growth factor, including those assessed with the MTT assay, when observed in other cell systems has been in this concentration range [15]. In the normal human osteoblastic cells used here, however, these concentrations did not produce significant effects on human osteoblastic cell activity assessed with the MTT assay that directly measures mitochondrial enzymatic activity and not proliferation of cells per se. Likewise, IGF-II added to the medium of the human osteoblastic cells did not produce significant effects on alkaline phosphatase activity. It should be noted here that the cells that were used in our present study are from the calvarium which is of intramembranous origin unlike the trabecular bone of endochondral origin used as a source of many of the cell cultures used in the studies cited above $[12,17,19]$.

There is substantial evidence from a variety of approaches that suggests that the effects of IGFs on osteoblastic cells and consequently on the skeleton in general, are decreased when endogenous activities of IGF are inhibited by IGF receptor antibodies, IGF antibodies, or inhibitory IGF binding proteins $[12,17,20]$. These data provide a basis for recognizing that endogenous as well as exogenous effects of IGF-II are important for the regulation of the skeleton.

The deregulation of the IGF-II system is linked to diverse pathologies and it is suggested that this growth factor plays a role in tumorigenesis, and is linked to different types of cancers such as liver, breast and prostate cancers 
[8]. Cancer cells expressing higher levels of IGF-II and its receptor IGF1R, are usually more aggressive and have a stronger tendency to metastasize [21].

Although there are indications that IGFs are involved in abnormal growth and malignant conditions, the studies conducted on the effects of IGF-II on osteosarcoma cells appear to be limited [21]. IGFs, however, have been found to be over expressed in a more aggressive type of osteosarcoma, and are associated with metastasis, chemotherapy resistance and lower survival rate [22,23].

The G292 cell line was used in this present study to help elucidate the effect of IGF-II in the pathogenesis and regulation of osteosarcoma and possible differences with those in normal human osteoblastic cells. Previous studies on the effects of IGFs in G292 cells have been limited but suggestive of an important growth regulatory role for these factors [24]. In a Kappel et al. study, it was shown that G292 cells, could show some, albeit low level of viability, in serum free medium for relatively long periods of time (5 weeks) in culture, unlike 4 other osteosarcoma cell lines, (HOS, MG-63, SaOS and U2) that showed essentially no cell activity. This maintenance level of activity in the G292 cells was significantly enhanced with the addition of IGF-I to the medium [24]. It was also observed in this study that endogenous production of IGF-I in the G-292 cells was barely detectable but that IGF-I receptors were demonstrated and that binding of IGF-II to these receptors also occurred [24]. In a series of preliminary studies conducted in our lab with G292 cells we found essentially no difference in cellular activity when cells were grown in serum or serum free medium suggesting that growth factors present exogenously might not greatly influence the growth of these osteosarcoma cells. However, with the addition of chromeceptin, a drug that has been shown in other cancer cells to inhibit endogenous levels of IGF-II there were significant decreases in activity of the G292 cells. These observations led to the present study that focuses more on the comparison of the effects of exogenous versus endogenous IGF-II effects in the G292 cells.

Chromeceptin has been shown in another system of cancer cells to be involved in the modulation of endogenous levels of IGF-II. It has been reported that chromeceptin inhibits insulin-induced adipogenesis and reduces the growth and viability of human hepatocellular carcinoma cells that over express IGF-II [9]. The method in which chromeceptin functions is by inducing the expression of IGF inhibitory genes, such as IGFBP-1 and suppressors of cytokine signaling 3 (SOCS-3) through activation of signal transducer and activator of transcription 6 (STAT6) [10].

The experiments conducted in this present study with chromeceptin show that this drug inhibits endogenous production of IGF-II levels in both normal human osteoblastic cells as well as the G292 osteosarcoma cells in a similar concentration dependent manner. Chromeceptin is also shown here in G292 cells to produce small, but significant increases in the levels of IGFBP-1 suggesting its mechanisms of action is similar to what has been described in other cancer cell systems [10]. The effects of chromeceptin on decreasing endogenous IGF-II levels in both G292 and normal osteoblastic cells paralleled its effects on cellular activity measured with the MTT assays suggesting an important role of endogenous IGF-II levels in cellular functions. It should be noted, however, that no significant effects of chromeceptin were observed on the marker of early differentiation, alkaline phosphatase, in the normal osteoblastic cells at a concentration that did have effects on endogenous IGF-II levels and MTT activity. The lack of effect of chromeceptin on alkaline phosphatase activity in the normal osteoblastic cells provides evidence that the drug at the concentrations employed is not toxic to the cells as supported by the lack of any apparent morphological effects of the drug on the cells as viewed by light microscopy. Collectively, therefore, our results with chromeceptin suggest that it can be a useful tool to further understand the role of endogenous IGF-II levels particularly in the proliferative functions of human osteoblastic and osteosarcoma cells.

In summary, this study provides data on the novel use of chromeceptin in both normal human osteoblasts as well as an osteosarcoma cell line to further delineate the roles of endogenous versus exogenous IGF-II in the regulation of their functional control. The results with the normal osteoblastic cells are consistent with the published data with osteoblastic cells from normal trabecular bone from noncalvarial sites (femoral head and iliac crest) in which exogenously added IGF-II at concentrations employed here does not have significant effects on alkaline phosphatase [19]. However, the lack of consistent, significant effects of added IGF-II on activity in the human osteoblastic cells from calvaria used here is in contrast to the increases in proliferation previously reported by other groups with osteoblastic cells from trabecular bone at femoral head and iliac crest sites [19]. Although there were some indications of an effect of exogenously added IGF-II on cell activity in the G292 osteosarcoma cells, inhibition of endogenous levels of this growth factor by chromeceptin 
had significant inhibitory effects on activity in these cells as well as the normal osteoblastic cells. Our studies thus provide supporting evidence that endogenous IGF-II can be a critical regulator of the activity of both normal osteoblasts and osteosarcoma cells. Chromeceptin, as an effective inhibitor of IGF-II in these cells, can therefore be an important pharmacological tool to further elucidate the role of this growth factor in skeletal regulation in both normal and pathological conditions.

\section{References}

1. Yakar S, Werner H, Rosen CJ. Insulin-like growth factors: actions on the skeleton. Journal of Molecular Endocrinology. 2018;61(1):T115-T137. doi: http:// dx.doi.org/10.1530/JME-17-0298

2. Canalis E. Growth factor control of bone mass. Journal of Cellular Biochemistry. 2009;108(4):769-777. doi: http://dx.doi.org/10.1002/jcb.22322

3. Wergedal JE, Mohan S, Lundy M, Baylink DJ. Skeletal growth factor and other growth factors known to be present in bone matrix stimulate proliferation and protein synthesis in human bone cells. Journal of Bone and Mineral Research. 1990;5(2):179-186. doi: http:// dx.doi.org/10.1002/jbmr.5650050212

4. Verhaar HJJ, Damen CA, Duursma SA, Scheven BAA. Comparison of the action of $17 \beta$-estradiol and progestins with insulin-like growth factors$\mid /-I I$ and transforming growth factor- $\beta 1$ on the growth of normal adult human bone-forming cells. Maturitas. 1995;21(3):237-243. doi: http://dx.doi. org/10.1016/0378-5122(94)00883-9

5. Canalis E, Gabbitas B. Bone morphogenetic protein 2 increases insulin-like growth factor I and II transcripts and polypeptide levels in bone cell cultures. Journal of Bone and Mineral Research. 2009;9(12):1999-2005. doi: http://dx.doi.org/10.1002/jbmr.5650091221

6. Pash JM, Delany AM, Adamo ML, Roberts CT, LeRoith $D$, Canalis E. Regulation of insulin-like growth factor I transcription by prostaglandin E2 in osteoblast cells. Endocrinology. 1995;136(1):33-38. doi: http://dx.doi. org/10.1210/endo.136.1.7828549

7. Strong DD, Beachler AL, Wergedal JE, Linkhart TA. Insulinlike growth factor II and transforming growth factor $\beta$ regulate collagen expression in human osteoblastlike cells in vitro. Journal of Bone and Mineral Research. 2009;6(1):15-23. doi: http://dx.doi. org/10.1002/jbmr.5650060105

8. Simpson A, Petnga W, Macaulay VM, WeyerCzernilofsky $U$, Bogenrieder T. Insulin-Like Growth
Factor (IGF) Pathway Targeting in Cancer: Role of the IGF Axis and Opportunities for Future Combination Studies. Targeted Oncology. 2017;12(5):571-597. doi: http://dx.doi.org/10.1007/s11523-017-0514-5

9. Choi Y, Kawazoe Y, Murakami K, Misawa H, Uesugi M. Identification of bioactive molecules by adipogenesis profiling of organic compounds. J Biol Chem. 2003;278(9):7320-7324. doi: http://dx.doi.org/10.1074/ jbc.M210283200

10. Choi Y, Shimogawa H, Murakami K, et al. Chemical Genetic Identification of the IGF-Linked Pathway that Is Mediated by STAT6 and MFP2. Chemistry \& Biology. 2006;13(3):241-249. doi: http://dx.doi.org/10.1016/j. chembiol.2005.12.011

11. Fanganiello RD, Ishiy FAA, Kobayashi GS, Alvizi L, Sunaga DY, Passos-Bueno MR. Increased In Vitro Osteopotential in SHED Associated with Higher IGF2 Expression When Compared with hASCs. Stem Cell Reviews and Reports. 2015;11(4):635-644. doi: http:// dx.doi.org/10.1007/s12015-015-9592-x

12. Scheven BA, Hamilton NJ, Fakkeldij TM, Duursma SA. Effects of recombinant human insulin-like growth factor I and II (IGF-I/-II) and growth hormone (GH) on the growth of normal adult human osteoblast-like cells and human osteogenic sarcoma cells. Growth Regul. 1991;1(4):160-167.

13. Barone A. Fabrication and Characterization of NanoCalcium Sulfate and Human Platelet Lysate as a Growth Factor Delivery System. International Journal of Dentistry and Oral Health. 2016;2(4). doi: http://dx.doi. org/10.16966/2378-7090.172

14. Laurel T, Perelman Karmon M, Nguyen D, Dziak R. Nanocalcium sulfate and collagen biomaterials: Effects on osteoblastic cells. Dental, Oral and Craniofacial Research. 2017;3(4). doi: http://dx.doi.org/10.15761/ DOCR.1000210

15. Wei-lian S, Li-li C, Jie Y, Zhong-sheng Y. Effects of IGF-II on promoting proliferation and regulating nitric oxide synthase gene expression in mouse osteoblast-like cell.J Zheijang Univ-Sci B. 2005;6(7):699-704. doi: http:// dx.doi.org/10.1007/BF02841041

16. Mohan S, Baylink DJ. Characterization of the IGF Regulatory System in Bone. In: Le Roith D, Raizada MK, eds. Current Directions in Insulin-Like Growth Factor Research. Vol 343. Boston, MA: Springer US; 1994:397406. doi: http://dx.doi.org/10.1007/978-1-4615-29880_37

17. Mohan S, Strong DD, Lempert UG, Tremollieres F, Wergedal JE, Baylink DJ. Studies on regulation of 
insulin-like growth factor binding protein (IGFBP)-3 and IGFBP-4 production in human bone cells. European Journal of Endocrinology. 1992;127(6):555-564. doi: http://dx.doi.org/10.1530/acta.0.1270555

18. Mccarthy TL, Centrella M, Canalis E. Regulatory Effects of Insulin-Like Growth Factors I and II on Bone Collagen Synthesis in Rat Calvarial Cultures*. Endocrinology. 1989;124(1):301-309. doi: http://dx.doi.org/10.1210/ endo-124-1-301

19. Langdahl BL, Kassem M, Møller MK, Eriksen EF. The effects of IGF-I and IGF-II on proliferation and differentiation of human osteoblasts and interactions with growth hormone. EurJ Clin Invest. 1998;28(3):176183.

20. Mohan S, Nakao Y, Honda Y, et al. Studies on the Mechanisms by Which Insulin-like Growth Factor (IGF) Binding Protein-4 (IGFBP-4) and IGFBP-5 Modulate IGF Actions in Bone Cells. Journal of Biological Chemistry. 1995;270(35):20424-20431. doi: http://dx.doi. org/10.1074/jbc.270.35.20424

21. Guerra FK, Eijan AM, Puricelli L, et al. Varying patterns of expression of insulin-like growth factors I and II and their receptors in murine mammary adenocarcinomas of different metastasizing ability. International Journal of Cancer. 1996;65(6):812820. doi: http://dx.doi.org/10.1002/(SICl)10970215(19960315)65:6<812::AID-IJC18>3.0.CO;2-5

22. Jentzsch T, Robl B, Husmann M, Bode-Lesniewska B, Fuchs B. Worse Prognosis of Osteosarcoma Patients Expressing IGF-1 on a Tissue Microarray. Anticancer Res. 2014;34(8):3881-3889.

23. Avnet S, Sciacca L, Salerno M, et al. Insulin Receptor Isoform A and Insulin-like Growth Factor II as Additional Treatment Targets in Human Osteosarcoma. Cancer Research. 2009;69(6):2443-2452. doi: http://dx.doi. org/10.1158/0008-5472.CAN-08-2645

24. Kappel CC, Velez-Yanguas MC, Hirschfeld S, Helman LJ. Human osteosarcoma cell lines are dependent on insulin-like growth factor I for in vitro growth. Cancer Res. 1994;54(10):2803-2807.

Copyright: (c) Nourah et al. This is an Open Access article distributed under the terms of the Creative Commons Attribution License, which permits unrestricted use, distribution, and reproduction in any medium, provided the original work is properly cited. 